\title{
Eighteen Years of Follow-up after Resection of a Giant Coronary Artery Aneurysm and Reconstruction with a Vein Graft
}

\author{
Yelee Kwon, M.D. ${ }^{1}$, Chong Bin Park, M.D., Ph.D. ${ }^{2}$, Pil Je Kang, M.D. ${ }^{1}$, Won Chul Cho, M.D., Ph.D. ${ }^{2}$ \\ 'Department of Thoracic and Cardiovascular Surgery, Asan Medical Center, University of Ulsan College of Medicine, Seoul; ${ }^{2}$ Department of Thoracic and \\ Cardiovascular Surgery, Gangneung Asan Hospital, University of Ulsan College of Medicine, Gangneung, Korea
}

\section{ARTICLE INFO}

Received August 18, 2020

Revised September 28, 2020

Accepted October 5, 2020

Corresponding author

Won Chul Cho

Tel 82-33-610-3267

Fax 82-33-640-8070

E-mail chomedy172@naver.com

ORCID

https://orcid.org/0000-0002-3858-6516
Giant coronary artery aneurysms are rare and challenging to treat because of variation in the presenting symptoms and the lack of established management guidelines. We report the case of a patient with a 6-cm-wide giant coronary artery aneurysm that was resected, followed by reconstruction using a saphenous vein graft and 18 years of follow-up.

Keywords: Coronary aneurysm, Saphenous vein

\section{Case report}

Giant coronary artery aneurysms larger than $2 \mathrm{~cm}$ in diameter are rare disease entities that can present with various symptoms [1]. Specific guidelines regarding the management of giant coronary artery aneurysms have not been established. We report a case of a patient with a 6 - $\mathrm{cm}$-wide giant coronary artery aneurysm that was resected, followed by reconstruction using a saphenous vein graft and 18 years of follow-up.

A previously healthy 29 -year-old man presented to Gangneung Asan Hospital with a complaint of chest discomfort. Computed tomography (CT) revealed a $6-\mathrm{cm}-$ wide mass-like lesion in the right heart, with limited resolution (Fig. 1). A 12-lead electrocardiogram showed normal sinus rhythm without signs of ischemia. Because acute intramural hematoma of the ascending aorta could not be ruled out at the time, we proceeded with an emergency operation.

A median full sternotomy was performed. After pericardiotomy, a 6-cm-wide giant coronary artery aneurysm was exposed, arising from the proximal part of the right coronary artery (RCA) and extending to the mid-RCA (Fig. 2A). The ascending aorta was normal. Cardiopulmonary bypass $(\mathrm{CPB})$ was initiated through the ascending aortic

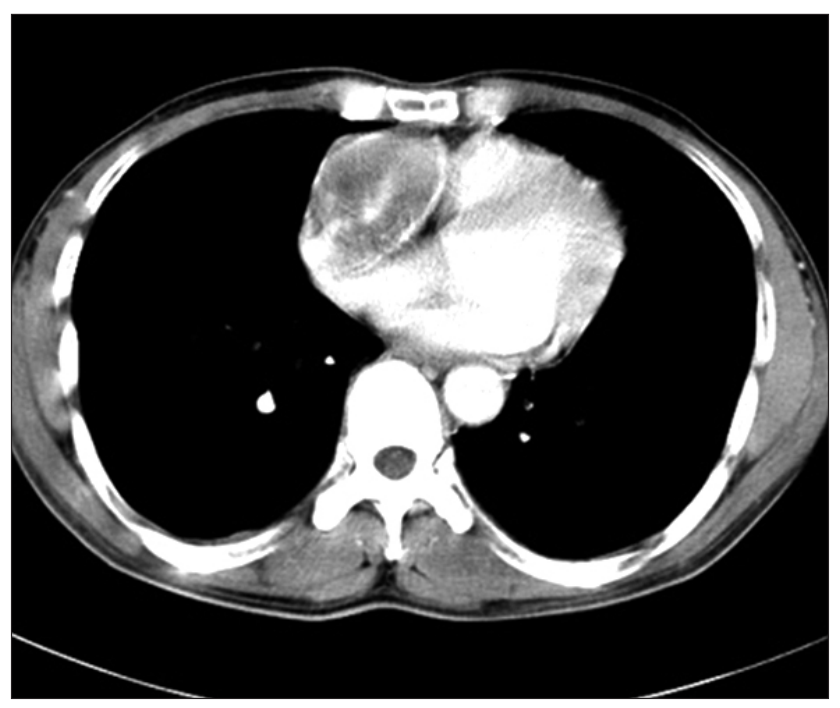

Fig. 1. Preoperative computed tomography image demonstrates a mass-like lesion in the right heart.

and right atrial cannulation. Antegrade cardioplegia (cold blood) was delivered via an aortic root cannula after aortic clamping. The aneurysm was resected, and the RCA was reconstructed using an approximately 6-cm-long saphenous vein graft with end-to-end anastomosis (Fig. 2B). The rest of the RCA was of normal size and had healthy vessel 

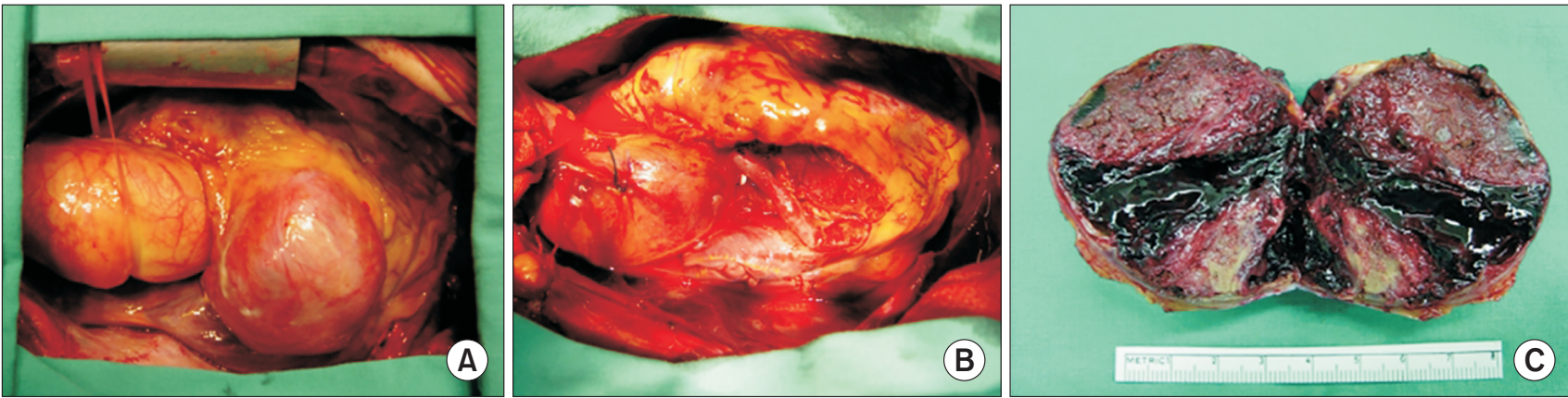

Fig. 2. Surgical images. (A) Intraoperative photograph of the giant coronary aneurysm. (B) Photograph taken after resection of the coronary artery aneurysm and reconstruction of the right coronary artery using a saphenous vein graft with end-to-end anastomosis. (C) Resected aneurysm with an organizing thrombus.

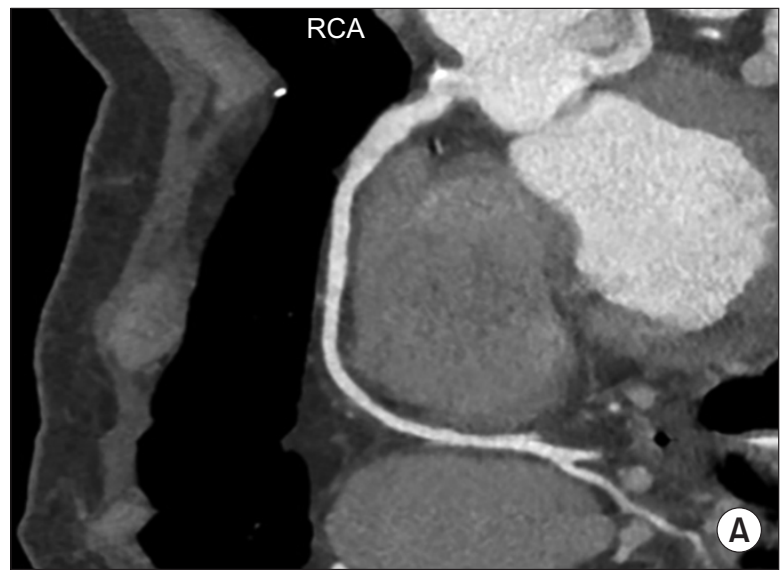

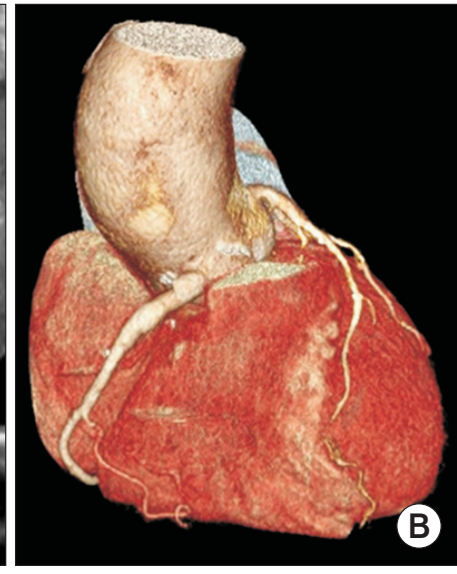

Fig. 3. (A, B) Follow-up computed tomography images 18 years after surgery showed patency of the saphenous vein graft. RCA, right coronary artery. walls, allowing proximal and distal end-to-end anastomosis. Fig. $2 \mathrm{C}$ shows an organizing thrombus inside the resected aneurysm. The patient was smoothly weaned from CPB.

The patient's postoperative course was uncomplicated. He was discharged on the 11th postoperative day, and there were no complications during 18 years of follow-up. The most recent follow-up CT scan showed a patent saphenous vein graft (Fig. 3). The patient was managed with dual antiplatelet therapy (100 mg of aspirin and $75 \mathrm{mg}$ of clopidogrel once daily) for 8 months postoperatively, after which he continued with $75 \mathrm{mg}$ of clopidogrel once daily.

The patient provided written informed consent for publication of his clinical details and images.

\section{Discussion}

In the present case, we demonstrated successful resection of a giant coronary aneurysm and arterial reconstruction with a saphenous vein graft with an excellent long-term outcome.
Giant coronary artery aneurysms can result from various causes, such as Kawasaki disease, syphilitic arteritis, trauma, and infectious arteritis [2]. The patient did not have a history of Kawasaki disease or trauma, and his laboratory and histopathologic findings did not support other underlying diagnoses. His syphilis test was non-reactive, and a histopathologic examination identified the resected specimen as arterial aneurysmal tissue with an organizing thrombus, combined with atherosclerosis but with no signs of an inflammatory response.

Previous studies have reported that coronary artery aneurysms could be misdiagnosed as paracardiac or intracardiac masses $[3,4]$. In this case, only CT was performed preoperatively, and the mass-like lesion in the right heart was initially misdiagnosed as an intramural hematoma of the ascending aorta. As the resolution of CT continues to improve, in conjunction with the implementation of electrocardiographic gating, coronary artery CT might be sufficient for diagnosing coronary artery aneurysms [5]. However, preoperative echocardiography or coronary angiography might have enabled the more accurate diagnosis 
of a thrombosed coronary aneurysm.

Because we performed end-to-end anastomosis rather than coronary artery bypass, this repair was more anatomical, without a size discrepancy. Since Cameron et al. [6] reported the cornerstone study demonstrating the use of the internal mammary artery for coronary artery bypass grafting, numerous studies have confirmed the superiority of arterial grafts over saphenous vein grafts. Therefore, we were concerned about the patency of the vein graft. Nonetheless, this patient experienced an excellent long-term postoperative course with a saphenous vein graft, with neither stenosis nor recurrent aneurysmal changes. Long-term maintenance with a single antiplatelet agent and lifestyle modifications, including regular exercise, may have influenced this outcome [7].

\section{Conflict of interest}

No potential conflict of interest relevant to this article was reported.

\section{ORCID}

Yelee Kwon: https://orcid.org/0000-0003-4386-7520

Chong Bin Park: https://orcid.org/0000-0003-3249-8782
Pil Je Kang: https://orcid.org/0000-0002-7587-0911

Won Chul Cho: https://orcid.org/0000-0002-3858-6516

\section{References}

1. Jha NK, Ouda HZ, Khan JA, Eising GP, Augustin N. Giant right coronary artery aneurysm: case report and literature review. J Cardiothorac Surg 2009;4:18.

2. Robinson FC. Aneurysms of the coronary arteries. Am Heart J 1985; 109:129-35.

3. Hirsch GM, Casey PJ, Raza-Ahmad A, Miller RM, Hirsch KJ. Thrombosed giant coronary artery aneurysm presenting as an intracardiac mass. Ann Thorac Surg 2000;69:611-3.

4. Quinn VJ, Baloch Z, Chandrasekaran K, Ross JJ, Karalis DG. Coronary artery aneurysm masquerading as a paracardiac mass on transesophageal echocardiography. Am Heart J 1994;127:441-3.

5. Karliova I, Fries P, Schmidt J, Schneider U, Shalabi A, Schafers HJ. Cardiac computed tomography as an imaging modality in coronary anomalies. Ann Thorac Surg 2018;105:e15-7.

6. Cameron A, Davis KB, Green G, Schaff HV. Coronary bypass surgery with internal-thoracic-artery grafts: effects on survival over a 15-year period. N Engl J Med 1996;334:216-9.

7. Angeloni E, Melina G, Benedetto U, et al. Metabolic syndrome affects midterm outcome after coronary artery bypass grafting. Ann Thorac Surg 2012;93:537-44. 